\title{
$\alpha$-Synuclein Interacts with Lipoproteins in Plasma
}

\author{
Fatemeh Nouri Emamzadeh $^{1}$ (D) $\cdot$ David Allsop ${ }^{1}$
}

Received: 16 May 2017 / Accepted: 16 August 2017 /Published online: 8 September 2017

(C) The Author(s) 2017. This article is an open access publication

\begin{abstract}
Parkinson's disease (PD) is an age-related neurodegenerative disorder characterized by dopaminergic neural cell death in the substantia nigra of the brain and $\alpha$-synuclein $(\alpha-$ syn) accumulation in Lewy bodies. $\alpha$-Syn can be detected in blood and is a potential biomarker for PD. It has been shown recently that $\alpha$-syn can pass through the blood-brain barrier (BBB), but the mechanism is not yet understood. We hypothesized that $\alpha$-syn could interact with lipoproteins, and in association with these particles, could pass through the BBB. Here, we show that apoE, apoJ, and apoA1, but not apoB, were co-immunocaptured along with $\alpha$-syn from human blood plasma, suggesting that $\alpha$-syn is associated with highdensity lipoproteins (HDL). This association was also supported by experiments involving western blotting of plasma fractions separated by gel filtration, which revealed that $\alpha$-syn was found in fractions identified as HDL. Interestingly, we could also detect $\alpha$-syn and ApoJ in the intermediate fraction between HDL and LDL, referred to as lipoprotein (a) (Lp(a)), which has an important role in cholesterol metabolism. Overall, the results provide best support for the hypothesis that $\alpha$-syn interacts with HDL, and this has potential implications for transport of $\alpha$-syn from the brain to peripheral blood, across the BBB.
\end{abstract}

Keywords Parkinson's disease (PD) · Blood-brain barrier $(\mathrm{BBB}) \cdot \alpha$-Synuclein $(\alpha$-syn $) \cdot$ Lipoproteins

Fatemeh Nouri Emamzadeh

fateme_nouri20@yahoo.com

1 Division of Biomedical and Life Sciences, Faculty of Health and Medicine, University of Lancaster, Lancaster LA1 4AY, UK

\section{Introduction}

Parkinson's disease (PD) is a progressive brain disorder, the main neuropathological feature of which is the degeneration of dopaminergic neurons in the substantia nigra (SN) pars compacta of the brain, resulting in tremor, muscle stiffness, and other motor and non-motor defects (Jankovic 2008). In this disease, a protein called $\alpha$-synuclein ( $\alpha$-syn) accumulates in an aggregated and fibrillar form within the Lewy bodies (LBs), which are found in surviving neurons of the SN and other brain regions (Spillantini et al. 1997). LBs are also present, but in more widespread areas of the brain, in dementia with Lewy bodies (DLB) (Spillantini et al. 1998).

It is now clear that $\alpha$-syn can be secreted from cells into the extracellular space and is found in human body fluids, including the cerebrospinal fluid (CSF) and blood plasma (El-Agnaf et al. 2003; Mollenhauer et al. 2011). This has led to considerable interest in $\alpha$-syn as a potential biomarker for PD and/or other $\alpha$-synucleinopathies (El-Agnaf et al. 2006; Hong et al. 2010; Foulds et al. 2011, 2013). Once initiated, the aggregation of $\alpha$-syn appears to spread throughout adjacent parts of the brain by propagation in a "prionoid" fashion (AlvarezErviti et al. 2011; Olanow and Brundin 2013; Aulić et al. 2014; Narkiewicz et al. 2014). These $\alpha$-syn aggregates may be harmful to dopaminergic neurons in the SN, especially when $\alpha$-syn is present in the form of toxic oligomers (Kalia et al. 2013).

It is well known that $\alpha$-syn interacts with lipids, resulting in its transition from a natively unfolded protein into a more helical structure (Auluck et al. 2010). Therefore, it is conceivable that $\alpha$-syn is associated with lipoprotein particles (such as VLDL, LDL, HDL, VHDL) in blood and in other tissues. If so, this would have important implications for the study of $\alpha$ syn as a potential biomarker, as well as for understanding its normal function and its role in disease. Apolipoproteins have 
11 amino acid repeats that mediate lipid interactions in a similar way to the $\mathrm{N}$-terminal $\alpha$-helices of $\alpha$-syn. Like $\alpha$-syn, apolipoproteins, with their amphipathic helices, can insert into lipid membranes and influence their curvature (Varkey et al. 2010).

A potential association between $\alpha$-syn and lipoproteins is also emerging from other observations. It is thought that $\alpha$-syn plays an important role in synaptic vesicle recycling at the dopaminergic synapse (Busch et al. 2014; Vargas et al. 2014), and the involvement of lipoproteins could provide a source of the negatively charged lipids required for expansion of synaptic membranes during formation and release of synaptic vesicles (Eichmann et al. 2016). Furthermore, $\alpha$-synlipoprotein interactions could also be involved in the transport of $\alpha$-syn across the blood-brain barrier (BBB). An imbalance in the flux of the $\beta$-amyloid $(A \beta)$ protein between the brain and blood, resulting in reduced brain amyloid clearance, has already been implicated as a possible causative event in Alzheimer's disease (Tarasoff-Conway et al. 2015), and the same could be true for $\alpha$-syn in PD and other $\alpha$ synucleinopathies. Indeed, it has been determined already that radiolabeled $\alpha$-syn can enter the CNS from the blood, and vice versa, implying its passage across the $\mathrm{BBB}$ (Sui et al. 2014). It is not yet clear whether this BBB transport depends on the intermediation of specific receptors or if $\alpha$-syn can simply diffuse across the BBB based on its amphipathic properties (Sui et al. 2014; Steiner et al. 2011). Also, it has been shown that deletion of $S N C A$ in knockout mice causes an increased level of brain cholesterol, suggesting that $\alpha$-syn is involved in the transport of cholesterol out of the brain (Barceló-Coblijn et al. 2007).

Here, we hypothesize that $\alpha$-syn is carried in the blood and/ or CSF in association with lipoproteins, and that this could aid its passage across the BBB. To investigate whether $\alpha$-syn exists in association with lipoproteins in blood plasma, we used different methods including immunoprecipitation, SDSPAGE/immunoblotting, plasma fractionation by gel filtration, and immunoassay. The experimental data support the idea that $\alpha$-syn is found in association with HDL in human blood.

\section{Material and Methods}

\section{Human Plasma Samples for $\alpha$-Synuclein/Apolipoprotein Study}

About $5 \mathrm{ml}$ of blood was collected from two healthy males, 24 and 27 years old, and one female, 25 years old, in tubes containing EDTA to prevent clotting. The separation of plasma was achieved within $2 \mathrm{~h}$ of blood collection by centrifugation at $3000 \mathrm{~g}$ and $15^{\circ} \mathrm{C}$ for $10 \mathrm{~min}$ to avoid red blood cell (RBC) rupture and hemolysis as a consequence of exposure to excessive heat or cold. Then, $1.5 \mathrm{ml}$ of plasma was transferred to plastic tubes containing a protease inhibitor cocktail consisting of $104 \mathrm{mM}$ AEBSF, $80 \mu \mathrm{M}$ aprotinin, $4 \mathrm{mM}$ bestatin, $1.4 \mathrm{mM}$ E64, $2 \mathrm{mM}$ leupeptin, and $1.5 \mathrm{mM}$ pepstatin A (Sigma P8340), and stored at $-80^{\circ} \mathrm{C}$. Moreover, to reduce hemolysis and destruction of RBC membrane, vigorous mixing or shaking was avoided. The samples were thawed at room temperature directly before analysis without repeated freeze/thaw cycles.

\section{Crosslinking of Anti- $\alpha$-syn Antibody to Dynabeads}

The beads (Pierce protein $\mathrm{A} / \mathrm{G}$ magnetic beads with binding capacity 55 to $85 \mu \mathrm{g}$ rabbit $\mathrm{IgG}$ per mg magnetic particles) were vortexed for 1-2 min to resuspend them in solution. Then, $100 \mu \mathrm{l}$ of beads was transferred to a $1.5-\mathrm{ml}$ plastic tube. The tube was placed in a Dynal magnetic particle concentrator (MPC) for $1 \mathrm{~min}$, and the fluid was removed. The beads were washed three times with $0.5 \mathrm{ml}$ of $0.1 \mathrm{M}$ phosphate buffer, $\mathrm{pH}$ 8.2. Four hundred microliters of $80 \mu \mathrm{g}$ antibody was added to the tube containing the beads, and incubated for 15-30 min with mixing by rotation at RT. These antibodies are Santa Cruz anti- $\alpha$-syn C211, sc-58480; Millipore antiapolipoprotein A1, AB740; Millipore anti-apolipoprotein B, AB742; Millipore anti-apolipoprotein B, AB947 and abcam anti-apolipoprotein $\mathrm{J}$, ab7621. The beads were washed three times with $0.5 \mathrm{ml}$ of $0.1 \mathrm{M}$ phosphate buffer, $\mathrm{pH} 8.2$ and washed again two times with $1 \mathrm{ml}$ of $0.2 \mathrm{M}$ triethanolamine, pH 8.2. Then, fresh $20 \mathrm{mM}$ DMP (dimethyl pimelinediimidate dihydrochloride) solution was prepared and $1 \mathrm{ml}$ of it was added to the beads and incubated for $30 \mathrm{~min}$ on the mixing rotator, at RT. The reaction was stopped by removing the DMP buffer from the beads and by adding $1 \mathrm{ml}$ of $50 \mathrm{mM}$ Tris-HCl, $\mathrm{pH}$ 7.4. The tube was mixed and incubated for $30 \mathrm{~min}$ on the rotator at RT. The beads were washed three times with $0.5 \mathrm{ml}$ PBS and washed again twice with $0.5 \mathrm{ml}$ citrate buffer $\mathrm{pH} 3.1$ and placed on the mixing rotator for 2 min each time. Finally, the beads were washed three times with PBS and stored in $0.5 \mathrm{ml}$ PBS. For long-term preservation, the beads were stored in PBS containing $0.05 \% \mathrm{NaN}_{3}$ at $4{ }^{\circ} \mathrm{C}$.

\section{Immunoprecipitation}

Fifty microliters of antibody-conjugated beads was transferred to a tube at RT. The tube was placed on the MPC for $1-2 \mathrm{~min}$, and the supernatant discarded. The beads were washed three times with $0.1 \mathrm{M}$ phosphate buffer, $\mathrm{pH}$ 8.2. One milliliter of plasma was added to the beads. The tube was incubated for $1 \mathrm{~h}$ on the mixing rotator at RT and then was placed on the MPC for $2 \mathrm{~min}$ and the supernatant discarded. Finally, the beads were washed up to seven times with PBS. 


\section{Elution Procedure}

For mild elution, $40 \mu$ of $0.1 \mathrm{M}$ citrate buffer, $\mathrm{pH} 3$, was added to the beads and incubated for 2 min on the mixing rotator at RT. The tube was placed on the magnet, and the supernatant, containing antigen, was transferred to a clean tube. The sample was then adjusted to physiological $\mathrm{pH}$ by adding $1 \mathrm{M}$ Tris, $\mathrm{pH} 7.5$.

For strong elution, the beads were boiled for $10 \mathrm{~min}$ in SDS gel loading buffer. The tube was placed on the magnet, and the supernatant, containing antigen, was transferred to a clean tube.

\section{Immunoblotting}

Fifteen percent acrylamide/bis-acrylamide gel was made using Sigma, A3699. A relevant molecular weight marker and the samples were loaded in the wells. The gel was run at $180 \mathrm{~V}$ for $1 \mathrm{~h}$ in running buffer containing $25 \mathrm{mM}$ Tris, $192 \mathrm{mM}$ glycine, and $0.1 \% \mathrm{SDS}, \mathrm{pH} \sim 8.5$. The separated proteins were transferred to a nitrocellulose membrane by wet transfer at $25 \mathrm{~V}$ for $1 \mathrm{~h}$ in transfer buffer containing $25 \mathrm{mM}$ Tris, $192 \mathrm{mM}$ glycine, and $20 \%$ methanol. Afterwards, the membrane was incubated in $25 \mathrm{ml}$ of $5 \%$ skimmed milk as blocking buffer for $1-2 \mathrm{~h}$ at room temperature, following by an optional wash of the membrane with PBS-T (10 mM sodium phosphate, $0.15 \mathrm{M} \mathrm{NaCl}, 0.05 \%$ Tween-20, pH 7.5). The membrane was then incubated with the primary antibody (at the appropriate dilution) in $10 \mathrm{ml}$ of $5 \%$ skimmed milk in PBS-T with gentle agitation overnight at $4{ }^{\circ} \mathrm{C}$. To remove unbound antibodies, the membrane was washed three times for $30 \mathrm{~min}$ each with PBS-T. The membrane was incubated with the secondary antibody, horseradish peroxidase (HRP) conjugated to goat anti-rabbit (DAKO, K1497), rabbit anti-goat (DAKO, P0449), or goat antimouse (DAKO, K4000) antibody, as appropriate, diluted in PBS-T. The membrane was incubated with the secondary antibody with gentle agitation for $45 \mathrm{~min}$ at RT followed by three washes of $30 \mathrm{~min}$ each with PBS-T. Finally, $1 \mathrm{ml}$ of luminol/ enhancer buffer and stable peroxide buffer (SuperSignal West Pico Chemiluminescent Substrate, Pierce 34079) was applied onto the membrane for $3 \mathrm{~min}$. Then, the membrane was drained of excess developing solution (without drying completely), wrapped in plastic film, and exposed to X-ray film.

\section{Gel Filtration Analysis of Plasma Lipids}

Blood was collected into the EDTA tube to stop clotting after a 4-5-h fast from a healthy volunteer (35 years old, male). Plasma was separated by centrifugation for $10 \mathrm{~min}$ at $1000 \mathrm{~g}$ and $0.2 \mathrm{ml}$ of plasma was loaded immediately onto two Superose-6 10/300GL columns connected in series to an
ÄKTA purifier system (GE Healthcare, MD, USA). Fractions of $0.5 \mathrm{ml}$ were collected using an elution buffer (1 mM EDTA, $154 \mathrm{mM} \mathrm{NaCl}$, and $0.02 \% \mathrm{NaN} 3, \mathrm{pH} 8.2$ ) at a flow rate of $0.5 \mathrm{ml} / \mathrm{min}$. The lipid contents (triglyceride, cholesterol) in individual fractions were determined with enzymatic assay kits (Chang et al. 1999). The size-fractionated samples of human plasma were prepared, with appropriate ethical approval from the donor concerned, by one of the collaborators in Japan (Dr. Takashi Kasai, Department of Neurology, Kyoto Prefectural University of Medicine).

\section{Immunoassay for Measuring Total $\alpha$-Syn}

An enzyme-linked immunosorbent assay (ELISA) plate was coated with $150 \mu \mathrm{l} /$ well of anti- $\alpha$-syn C211 antibody (Santa Cruz, sc-12767), diluted $1 \mu \mathrm{g} / \mathrm{ml}$ in $200 \mathrm{mM} \mathrm{NaHCO} 3$, $\mathrm{pH} 9.6$, and incubated at $4{ }^{\circ} \mathrm{C}$ overnight. The wells were then washed four times with PBS containing $0.05 \%$ Tween-20 (PBS-T), and incubated for $2 \mathrm{~h}$ at $37^{\circ} \mathrm{C}$ with $200 \mu \mathrm{l} /$ well of freshly prepared blocking buffer $2.5 \%$ fish gelatin, Sigma G7765, in PBS-T. The plate was washed again with PBS-T. One hundred fifty microliters of plasma fraction samples was added to each well, and the assays were performed in triplicate. Following this, the plate was incubated at $37^{\circ} \mathrm{C}$ for $2 \mathrm{~h}$. After a repeat wash with PBS-T, $100 \mu \mathrm{l} /$ well of the detection antibody, anti- $\alpha / \beta / \gamma$-synuclein FL140 antibody (Santa Cruz, sc-10717), dilution 1:1000 in blocking buffer, was added, and the plate incubated at $37^{\circ} \mathrm{C}$ for $2 \mathrm{~h}$. After another wash with PBS-T, the plate was incubated with $100 \mu \mathrm{l} /$ well of the secondary antibody (goat anti-rabbit HRP, dilution 1:10,000) in blocking buffer at $37^{\circ} \mathrm{C}$ for $2 \mathrm{~h}$. The plate was then washed again with PBS-T before adding $100 \mu \mathrm{l} /$ well of Sure Blue TMB Microwell Peroxidase Substrate (KPL, USA) and leaving the color to develop for $30 \mathrm{~min}$ at RT. Finally, $100 \mu \mathrm{l} /$ well of stop solution was added and absorbance at $450 \mathrm{~nm}$ determined.

\section{Production of Recombinant $\alpha$-Synuclein Protein}

Recombinant $\alpha$-syn (R- $\alpha$-syn) protein was produced by using a pET11a expression vector introduced into Escherichia coli (Emamzadeh et al. 2016).

\section{Results}

To investigate whether $\alpha$-syn interacts with lipoproteins in human blood plasma, a sample of plasma from a healthy individual was incubated with protein $\mathrm{A} / \mathrm{G}$ dynabeads crosslinked with anti- $\alpha$-syn C211 antibody, and, after extensive washing, the resulting immunocaptured material was eluted from the beads, fractionated on 15\% SDS-PAGE gels, and immunoblotted to detect $\alpha$-syn (Fig. 1) as well as 


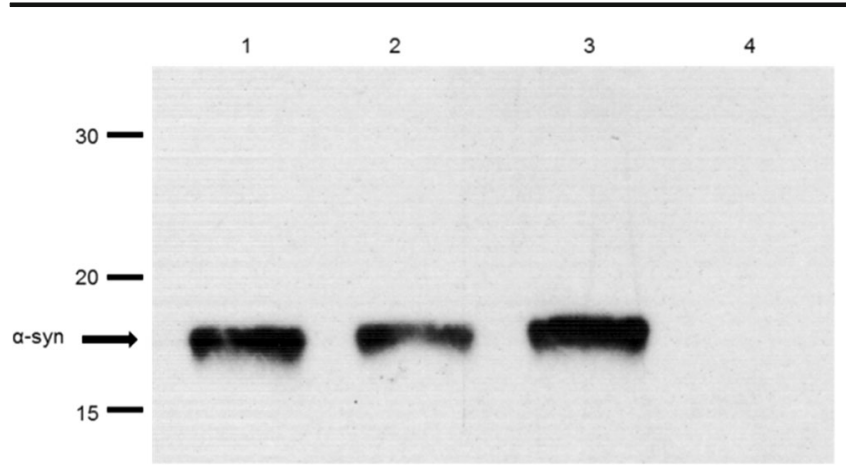

Fig. 1 Immunocapture of $\alpha$-syn by C211-dynabeads. Plasma, R- $\alpha$-syn (positive control), or PBS (negative control) were incubated with magnetic dynabeads coupled to C211 anti- $\alpha$-syn antibody ("beads + $\mathrm{Ab}$ "). Whole plasma was also incubated with empty "beads" (without any antibody). The immunoprecipitants were run on a $15 \%$ SDS-PAGE gel and immunoblotted with FL140 antibody (1:1500). Lane $1=50 \mathrm{ng}$ of $\mathrm{R}-\alpha$-syn; Lane 2 = eluant from beads exposed to R- $\alpha$-syn; Lane 3 = eluant from beads exposed to plasma; Lane $4=$ eluant from unconjugated beads exposed to plasma

apolipoproteins including apoA1 (Fig. 2a), apoB (Fig. 2b), apoE (Fig. 2c), and apoJ (Fig. 2d). In each case, samples of whole plasma, diluted 1/300 in PBS, were also included on the gels as a positive control for detection of each of these apolipoproteins. Plasma was also incubated with unconjugated beads as a control for non-specific binding of plasma proteins to the beads in the absence of $\mathrm{C} 211$ capture antibody. Antibody-coupled beads were also incubated with PBS to control for elution of non-plasma components (e.g., C211 heavy and light chains) from the beads. The results, presented in Fig. 2, show that apoA1 (28 kDa), apoE (34 kDa), and apoJ (80 kDa) were co-eluted with $\alpha$-syn, but apoB (500 kDa) was not detected in the eluant from the beads. ApoB was, however, easily detected in whole plasma (Fig. 2b). There was no evidence for non-specific binding of any of these apolipoproteins to unconjugated beads. Therefore, the results show that apoE, apoA1, and apoJ, but not apoB, were captured from plasma along with $\alpha$-syn.

To confirm these results, plasma samples were incubated with protein $\mathrm{A} / \mathrm{G}$ dynabeads cross-linked with antiapolipoprotein antibodies, and after extensive washing, the resulting immunocaptured material was eluted from the beads, fractionated on $15 \%$ SDS-PAGE gels, and immunoblotted to detect $\alpha$-syn (Fig. 3). As positive controls for detection of $\alpha$ syn, $50 \mathrm{ng}$ of recombinant $\alpha$-syn (R- $\alpha$-syn) and $10 \mu \mathrm{l}$ of diluted plasma were also included on the gel. Plasma was also incubated with unconjugated beads as a control for nonspecific binding of plasma proteins to the beads in the absence of capture antibody. Antibody-coupled beads were also incubated with PBS to control for elution of non-plasma components (e.g., antibody heavy and light chains) from the beads. The results show that $\alpha$-syn is co-immunocaptured by apoE, apoA1, and apoJ antibodies, but not with anti-apoB antibody, as shown in Fig. 2.

To shed more light on possible associations between $\alpha$-syn and lipoproteins, an alternative approach was taken by fractionating plasma into different lipoprotein components by gel filtration chromatography, followed by detection of $\alpha$-syn in these fractions by ELISA and by western blotting. The sizefractionated samples of human plasma were prepared by utilizing two Superose-6 10/300GL gel filtration columns connected in tandem, to provide sufficient separation power for the lipoprotein fractions. The lipid (cholesterol and

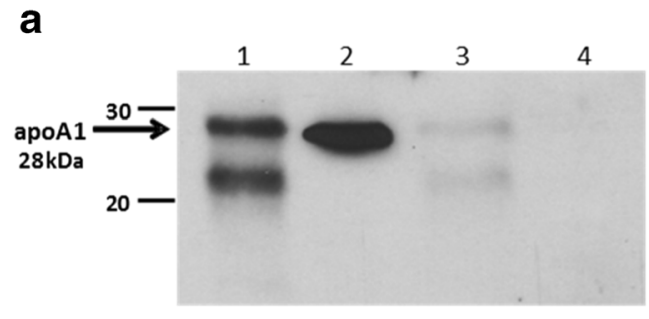

b

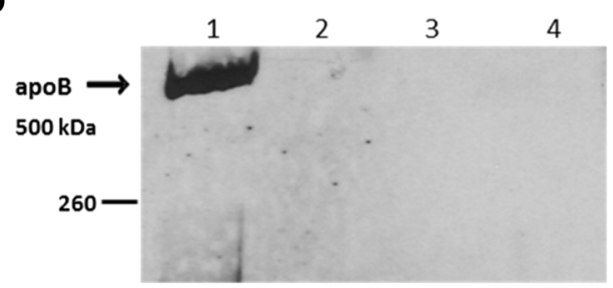

Fig. 2 Detection by SDS-PAGE/immunoblotting of apolipoproteins in material captured from plasma by dynabeads cross-linked with anti- $\alpha$-syn antibody C211. a Mild elution by citrate followed by immunoblotting with anti-apoA1. b Elution by SDS followed by immunoblotting with anti-apoB. $\mathbf{c}$ Elution by SDS followed by immunoblotting with anti-apoE. d Elution by SDS followed by immunoblotting with anti-apoJ. In each
C

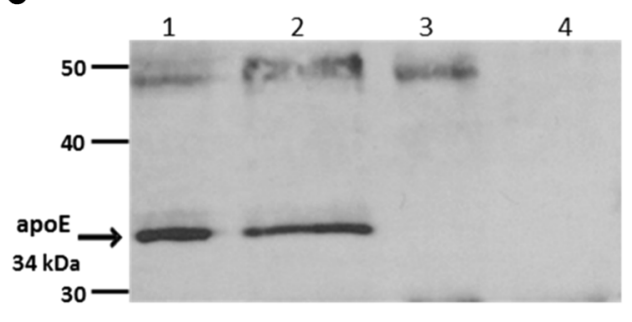

d

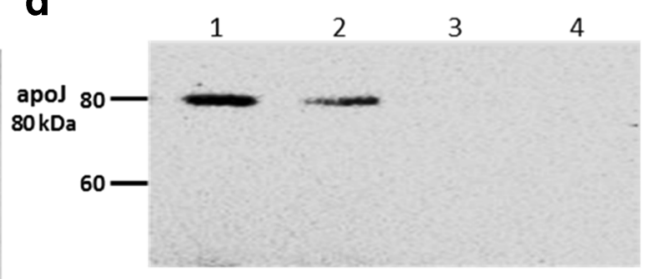

case: Lane 1 = apolipoprotein standard; Lane 2 = eluant from beads exposed to plasma; Lane 3 = eluant from unconjugated beads exposed to plasma; Lane 4 = eluant from conjugated beads exposed to PBS. Numbers on LHS indicate positions of MW standards (in $\mathrm{kDa}$ ). Bands corresponding to apoA1, apoB, apoE, and apoJ are also indicated 


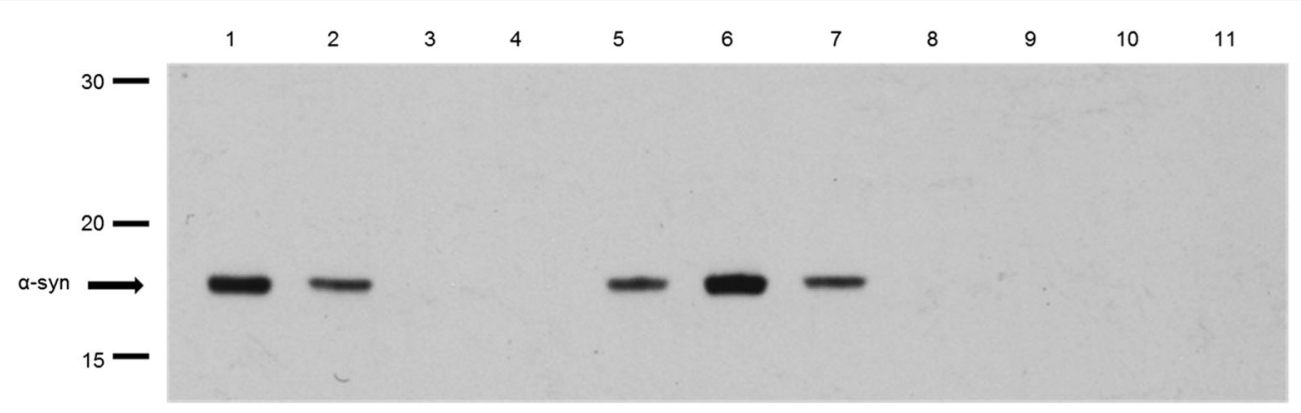

Fig. 3 Detection of $\alpha$-syn by anti- $\alpha$-syn antibody C211in material captured from plasma by dynabeads cross-linked with antiapolipoprotein antibodies. Lane $1=50 \mathrm{ng}$ of R- $\alpha$-syn as positive control; Lane 2 = whole plasma as a positive control; Lane 3 = eluant from unconjugated beads exposed to plasma as a negative control; Lane $4=$ eluant from conjugated beads with anti-apoB antibody exposed to plasma. Lane 5 = eluant from conjugated beads with anti-apoA1 antibody exposed to plasma. Lane $6=$ eluant from conjugated beads with anti-apo $J$

triglyceride) content of the 70 individual $0.5-\mathrm{ml}$ fractions eluted from this system was determined, to help identify the lipoproteins present. Figure 4 shows separation of VLDL (fractions 4-9), LDL (fractions 10-15), and HDL (fractions 27-33) components from this column.

A sandwich ELISA for $\alpha$-syn revealed that most of this protein was detected as a large and broad peak covering fractions 25-39 (Fig. 5), possibly with some other much smaller peaks on either side of this broad peak. When all 70 plasma fractions were subjected to SDS-PAGE/immunoblotting, employing anti- $\alpha$-syn $\mathrm{C} 211$ antibody, $\alpha$-syn was detected in fractions 19-24 relevant to the intermediate fraction between HDL and LDL (Lp(a)) and 27-34 relevant to HDL fractions and mainly in fractions $23-24$ and 30-32 (Fig. 6). Fractions 9-40 from the plasma gel filtration experiment, which include those fractions that contain $\alpha$-syn, were analyzed by SDSPAGE/immunoblotting to determine which apolipoproteins are present, by employing anti-apoE, anti-apoA1, anti-apoJ, and anti-apoB antibodies (all diluted to 1:5000 in PBS-T). ApoE was present in all of these fractions. ApoA1 was also antibody exposed to plasma. Lane $7=$ eluant from conjugated beads with anti-apoE antibody exposed to plasma. Lane $8=$ eluant from conjugated beads with anti-apoB antibody exposed to PBS. Lane $9=$ eluant from conjugated beads with anti-apoA1 antibody exposed to PBS. Lane $10=$ eluant from conjugated beads with anti-apoJ antibody exposed to PBS. Lane 11 = eluant from conjugated beads with anti-apoE antibody. Numbers on LHS indicate positions of MW standards (in $\mathrm{kDa}$ ). Bands corresponding to $\alpha$-syn are also indicated

present in all of these fractions, although fractions 9-11 gave only faint bands, and fractions 21-24 and 31-34 had more intense bands. Figure 7 shows that apoJ was mainly present in fractions 17-21 that are related to ( $L p(a))$ and fractions 28 31 that are HDL-containing fractions.

\section{Discussion}

$\alpha$-Syn could interact with either the lipid components or the apolipoprotein components of lipoproteins. A potential interaction with lipids is strongly suggested by the fact that the $\mathrm{N}$ terminal and $\mathrm{C}$-terminal regions of $\alpha$-syn can bind to fatty acids (Sharon et al. 2001) and $\alpha$-syn can also interact with the cholesterol component of lipoproteins via its cholesterolbinding domain (Fantini et al. 2011). The potential role of $\alpha$ syn in brain cholesterol homeostasis (Barceló-Coblijn et al. 2007), together with these lipid-binding properties of $\alpha$-syn (Eichmann et al. 2016; Varkey et al. 2013), encouraged us to

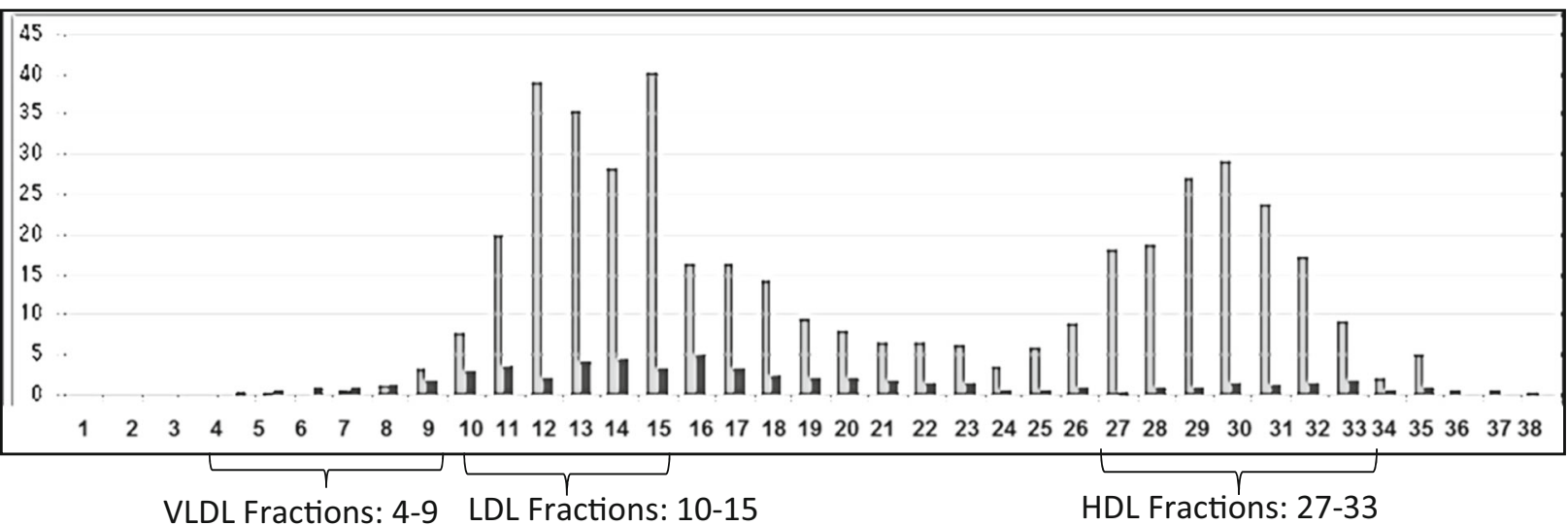

Fig. 4 The chart shows which fractions are related to VLDL, LDL, and HDL, based on size exclusion chromatography and cholesterol analysis 
Fig. 5 Measured ELISA absorbance values for $\alpha$-syn from fractionated plasma samples. The same ELISA system as presented above was used to detect $\alpha$-syn in the blood plasma fractions eluted from the tandem Superose-6 10/ 300GL column system. Most of the $\alpha$-syn appears to be present in fractions $25-39$, but there are also some smaller peaks present

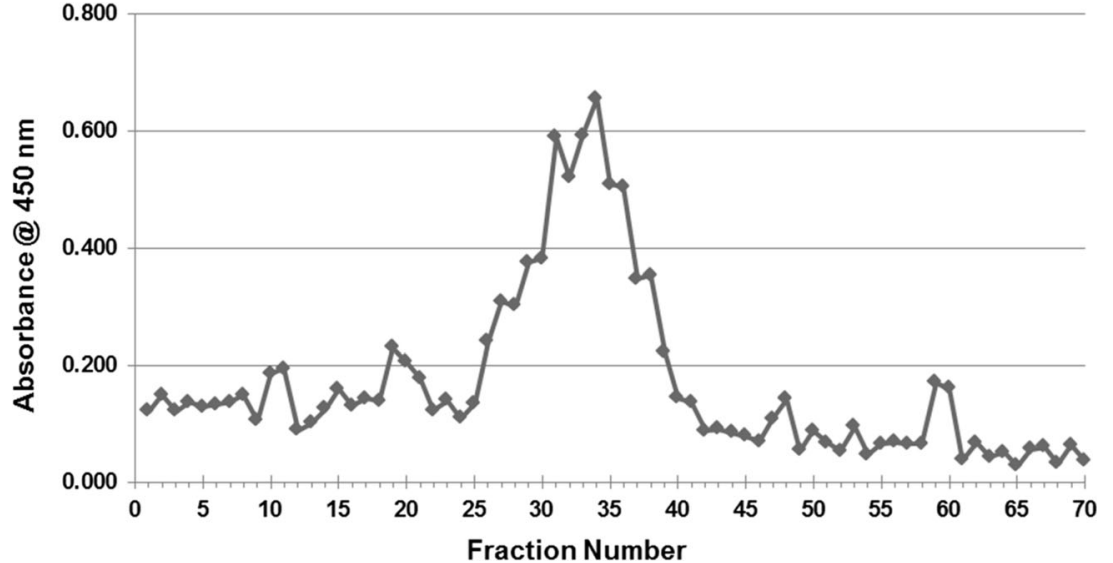

examine a possible association between $\alpha$-syn and lipoprotein particles in blood plasma.

The immunoprecipitation experiment showed that $\alpha$-syn appears to interact either directly or indirectly with apoA1, apoE, and apoJ. All of these apolipoproteins are found in the HDL sub-fraction of lipoproteins. ApoA1 is one of the exchangeable apolipoproteins that are actively involved in the regeneration of neuronal cells after injury, and CSF apoA1 levels have been shown to increase with the severity of macaque brain injury (Merched et al. 2000). ApoA1, as the main component of HDL, is also necessary for cholesterol transportation in the brain, and the plasma level of apoA1 is lower in PD patients than that in normal individuals, indicating a possible role for apoA1 in the pathogenesis of PD (Swanson et al. 2015; Qiang et al. 2013; Wang et al. 2010). We hypothesize that HDL, containing apoA1, may be involved in the transport of $\alpha$-syn out of the brain. The gel filtration results also revealed that $\alpha$-syn was detected in the fractions containing high levels of apoA1 and apoJ. These fractions are also related to HDL, based on size exclusion chromatography and cholesterol analysis.

Moreover, we found that $\alpha$-syn was also present in the intermediate fractions between HDL and LDL. The intermediate fraction between HDL and LDL is referred to as lipoprotein (a) $(\mathrm{Lp}(\mathrm{a}))$ and is a risk factor for cardiovascular disease. $\mathrm{Lp}$ (a) has an important role in cholesterol metabolism,

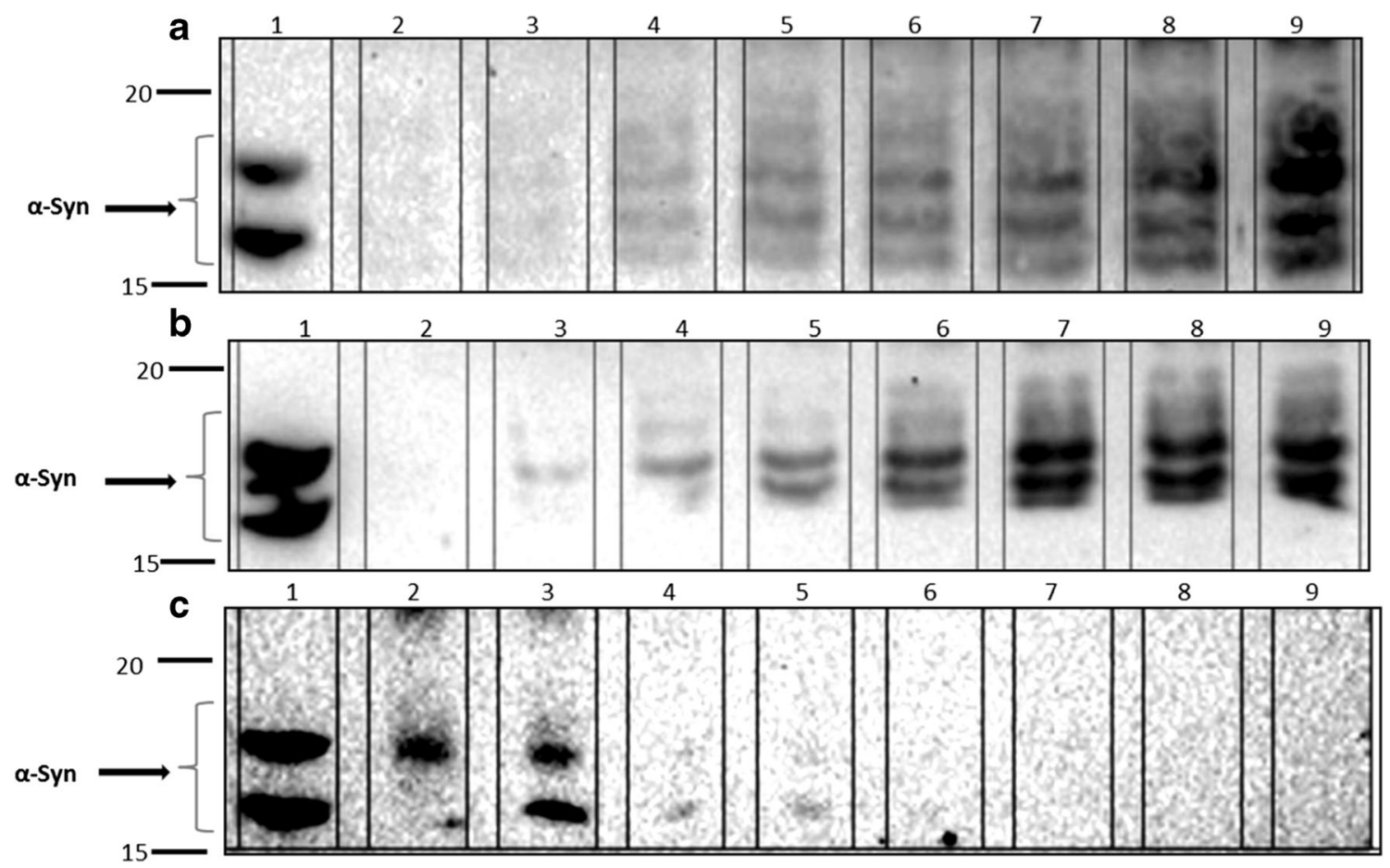

Fig. 6 Fractions 17-40 were fractionated on a 12\% SDS-PAGE gel and probed with anti- $\alpha$-syn C211 antibody (1:1000). a Lane $1=\mathrm{R}-\alpha$-syn as a positive control. Lanes $2-9$ are fractions $17-24$. b Lane $1=\mathrm{R}-\alpha$-syn as a positive control. Lanes $2-9$ are fractions $25-32$. c Lane $1=\mathrm{R}-\alpha$-syn as a positive control. Lanes 2-9 are fractions 33-40 


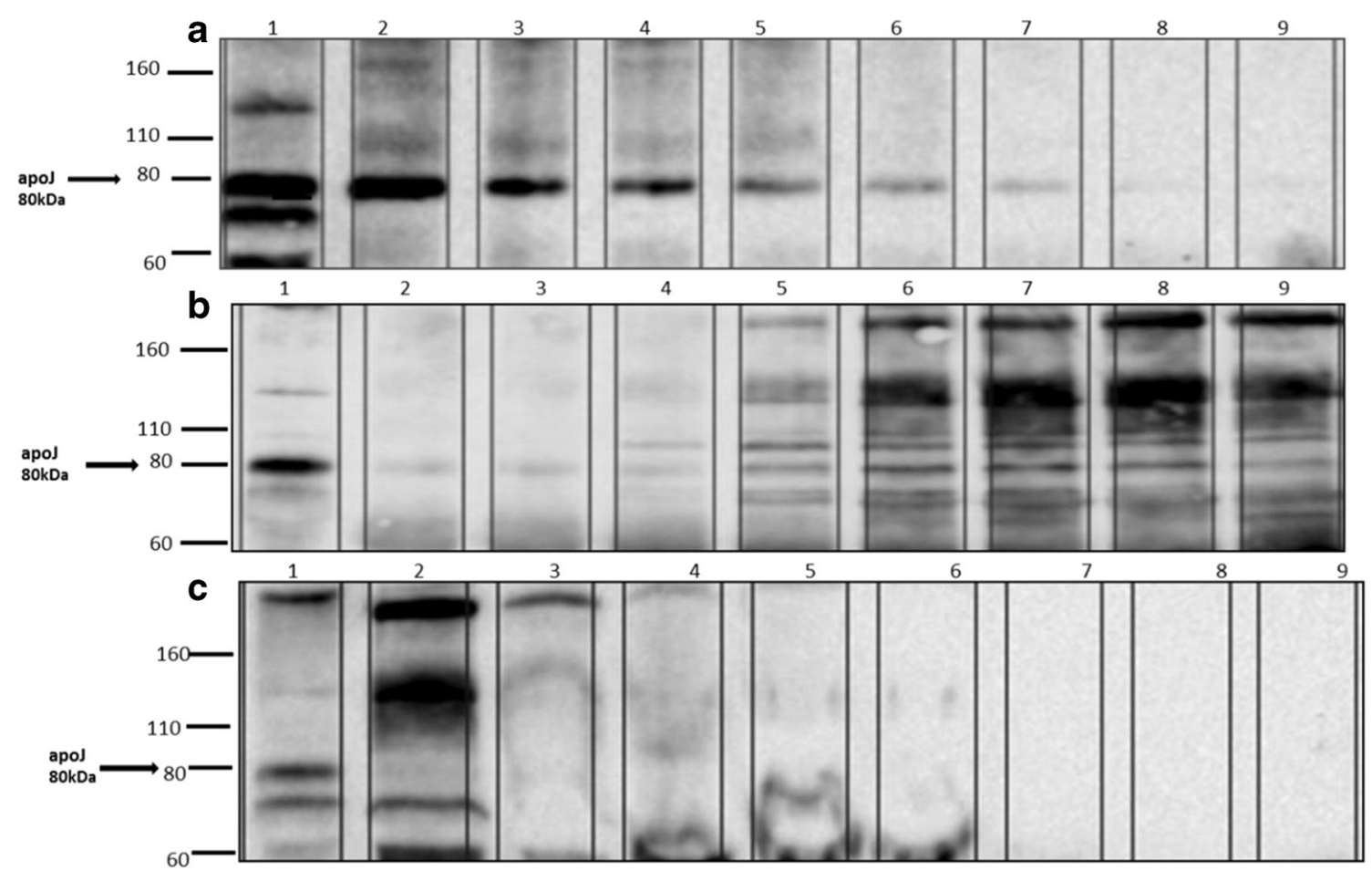

Fig. 7 Fractions 17-40 were fractionated on a 12\% SDS-PAGE gel and probed with anti-apoJ antibody (1:5000). a Lane $1=$ whole plasma as a positive control. Lanes 2-9 are fractions $17-24$. b Lane $1=$ whole plasma as a positive control. Lanes 2-9 are fractions 25-32. c Lane $1=$ whole plasma as a positive control. Lanes $2-9$ are fractions $33-40$

$\alpha$-syn, $\alpha$-Synuclein; Apo, apolipoproteins; BBB, bloodbrain barrier; CNS, central nervous system; CSF, cerebrospinal fluid; ELISA, enzyme-linked immunosorbent assay; LB, Lewy bodies; LRP1, low-density lipoprotein receptor-related protein-1; PD, Parkinson's disease; SN, substantia nigra

Acknowledgements This research was supported by an EC Framework 7 Marie Curie Fellowship Training Network Grant (NEURASYNC) on " $\alpha$-Synuclein-Related Brain Diseases." I thank our colleagues especially Dr. Takashi Kasai from Kyoto Prefectural University of Medicine who assisted with the research.

\section{Compliance with Ethical Standards}

Competing Interests The authors declare that they have no competing interests.

Open Access This article is distributed under the terms of the Creative Commons Attribution 4.0 International License (http:// creativecommons.org/licenses/by/4.0/), which permits unrestricted use, distribution, and reproduction in any medium, provided you give appropriate credit to the original author(s) and the source, provide a link to the Creative Commons license, and indicate if changes were made.

\section{References}

Alvarez-Erviti L, Seow Y, Schapira AH, Gardiner C, Sargent IL, Wood MJ, Cooper JM (2011) Lysosomal dysfunction increases exosome-mediated alpha-synuclein release and transmission. Neurobiol Dis 42:360-367 tions for transport of a-syn in the blood, and across the BBB. 
Aulić S, Le TT, Moda F, Abounit S, Corvaglia S, Casalis L, Gustincich S, Zurzolo C, Tagliavini F, Legname G (2014) Defined $\alpha$-synuclein prion-like molecular assemblies spreading in cell culture. BMC Neurosci 15:69

Auluck PK, Caraveo G, Lindquist S (2010) $\alpha$-Synuclein: membrane interactions and toxicity in Parkinson's disease. Annu Rev Cell Dev Biol 26:211-233

Barceló-Coblijn G, Golovko MY, Weinhofer I, Berger J, Murphy EJ (2007) Brain neutral lipids mass is increased in $\alpha$-synuclein geneablated mice. Neurochem 101:132-141

Busch DJ, Oliphint PA, Walsh RB, Banks SM, Woods WS, George JM, Morgan JR (2014) Acute increase of $\alpha$-synuclein inhibits synaptic vesicle recycling evoked during intense stimulation. Mol Biol Cell 25:3926-3941

Chang BH, Liao W, Li L, Nakamuta M, Mack D, Chan L (1999) Liverspecific inactivation of the abetalipoproteinemia gene completely abrogates very low density lipoprotein/low density lipoprotein production in a viable conditional knockout mouse. J Biol Chem 274:6051-6055

Cermenati G, Brioschi E, Abbiati F, Melcangi RC, Caruso D, Mitro N (2013) Liver X receptors, nervous system, and lipid metabolism. J Endocrinol Investig 36:435-443

Eichmann C, Campioni S, Kowal J, Maslennikov I, Gerez J, Liu X, Verasdonck J, Nespovitaya N, Choe S, Meier B, Picotti P, Rizo J, Stahlberg H, Riek R (2016) Preparation and characterization of stable $\alpha$-synuclein lipoprotein particles. J Biol Chem

El-Agnaf OMA, Salem SS, Paleologou KE, Gibson MJ, Curran MD, Court JA, Mann DMA, Ikeda SI, Cookson MR, Hardy J, Allsop D (2003) $\alpha$-Synuclein implicated in Parkinson's disease is present in extracellular biological fluids, including human plasma. FASEB J 17:1945-1947

El-Agnaf OMA, Salem SA, Paleologou KE, Curran MD, Gibson MJ, Court JA, Schlossmacher MG, Allsop D (2006) Detection of oligomeric forms of $\alpha$-synuclein protein in human plasma as a potential biomarker for Parkinson's disease. FASEB J 20:419-425

Emamzadeh FN, Aojula H, McHugh PC, Allsop D (2016) Effects of different isoforms of apoE on aggregation of the $\alpha$-synuclein protein implicated in Parkinson's disease. Neurosci Lett 618:146-151

Fantini J, Barrantes FJ (2013) How cholesterol interacts with membrane proteins: an exploration of cholesterol-binding sites including CRAC, CARC, and tilted domains. Front Physiol 4:31

Fantini J, Carlus D, Yahi N (2011) The fusogenic tilted peptide (67-78) of $\alpha$-synuclein is a cholesterol binding domain. Biochim Biophys Acta 1808:2343-2351

Foulds PG, Mitchell JD, Parker A, Turner R, Green G, Diggle P, Hasegawa M, Taylor M, Mann D, Allsop D (2011) Phosphorylated $\alpha$-synuclein can be detected in blood plasma and is potentially a useful biomarker for Parkinson's disease. FASEB J 25:4127-4137

Foulds PG, Diggle P, Mitchell JD, Parker A, Hasegawa M, MasudaSuzukake M Mann DMA, Allsop D (2013) A longitudinal study on $\alpha$-synuclein in blood plasma as a biomarker for Parkinson's disease. Sci Rep 3, https://doi.org/10.1038/srep02540 (2103)

Gelissen IC, Hochgrebe T, Wilson MR, Easterbrook-Smith SB, Jessup W, Dean RT, Brown AJ (1998) Apolipoprotein J (clusterin) induces cholesterol export from macrophage-foam cells: a potential antiatherogenic function? Biochem J 331(Pt 1):231-237

Hong Z, Shi M, Chung KA, Quinn JF, Peskind ER, Galasko D, Jankovic J, Zabetian CP, Leverenz JB, Baird G, Montine TJ, Hancock AM, Hwang H, Pan C, Bradner J, Kang UJ, Jensen PH, Zhang J (2010) DJ-1 and alpha-synuclein in human cerebrospinal fluid as biomarkers of Parkinson's disease. Brain 133:713-726

Jankovic J (2008) Parkinson's disease: clinical features and diagnosis. J Neurol Neurosurg Psychiatry 79:368-376

Kalia LV, Kalia SK, McLean PJ, Lozano AM, Lang AE (2013) $\alpha$ Synuclein oligomers and clinical implications for Parkinson disease. Ann Neurol 73:155-169
Merched A, Xia Y, Visvikis S, Serot JM, Siest G (2000) Decreased highdensity lipoprotein cholesterol and serum apolipoprotein AI concentrations are highly correlated with the severity of Alzheimer's disease. Neurobiol Aging 21:27-30

Mollenhauer B, Locascio JJ, Schulz-Schaeffer W, Sixel-Döring F, Trenkwalder C, Schlossmacher MG (2011) $\alpha$-Synuclein and tau concentrations in cerebrospinal fluid of patients presenting with parkinsonism: a cohort study. Lancet Neurol 10:230-240

Narkiewicz J, Giachin G, Legname G (2014) In vitro aggregation assays for the characterization of $\alpha$-synuclein prion-like properties. Prion 8:19-32

Nordestgaard BG, Chapman MJ, Ray K, Borén J, Andreotti F, Watts GF, Ginsberg H, Amarenco P, Catapano A, Descamps OS, Fisher E, Kovanen PT, Kuivenhoven JA, Lesnik P, Masana L, Reiner Z, Taskinen MR, Tokgözoglu L, Tybjærg-Hansen A, European Atherosclerosis Society Consensus Panel (2010) Lipoprotein(a) as a cardiovascular risk factor: current status. Eur Heart J 31:2844-2853

Olanow CW, Brundin P (2013) Parkinson's disease and alpha synuclein: is Parkinson's disease a prion-like disorder? Mov Disord 28:31-40

Qiang JK, Wong YC, Siderowf A, Hurtig HI, Xie SX, Lee VM, Trojanowski JQ, Yearout DB, Leverenz J, Montine TJ, Stern M, Mendick S, Jennings D, Zabetian C, Marek K, Chen-Plotkin AS (2013) Plasma apolipoprotein A1 as a biomarker for Parkinson disease. Ann Neurol 74:119-127

Sharon R, Goldberg MS, Bar-Josef I, Betensky RA, Shen J, Selkoe DJ (2001) alpha-Synuclein occurs in lipid-rich high molecular weight complexes, binds fatty acids, and shows homology to the fatty acidbinding proteins. Proc Natl Acad Sci U S A 98:9110-9115

Spillantini MG, Schmidt ML, Lee VM, Trojanowski JQ, Jakes R, Goedert M (1997) $\alpha$ Synuclein in Lewy bodies. Nature 388:839-840

Spillantini MG, Crowther RA, Jakes R, Hasegawa M, Goedert M (1998) $\alpha$-Synuclein in filamentous inclusions of Lewy bodies from Parkinson's disease and dementia with Lewy bodies. Proc Natl Acad Sci U S A 95:6469-6473

Steiner JA, Angot E, Brundin P (2011) A deadly spread: cellular mechanisms of $\alpha$-synuclein transfer. Cell Death Differ 18:1425-1433

Sui YT, Bullock KM, Erickson MA, Zhang J, Banks WA (2014) Alpha synuclein is transported into and out of the brain by the blood-brain barrier. Peptides 62:197-202

Swanson CR, Berlyand Y, Xie SX, Alcalay RN, Chahine LM, ChenPlotkin AS (2015) Plasma apolipoprotein A1 associates with age at onset and motor severity in early Parkinson's disease patients. Mov Disord 30:1648-1656

Tarasoff-Conway JM, Carare RO, Osorio RS, Glodzik L, Butler T, Fieremans E, Axel L, Rusinek H, Nicholson C, Zlokovic BV, Frangione B, Blennow K, Ménard J, Zetterberg H, Wisniewski T, de Leon MJ (2015) Clearance systems in the brain - implications for Alzheimer disease. Nat Rev Neurol 11:457-470

Vargas KJ, Makani S, Davis T, Westphal CH, Castillo PE, Chandra SS (2014) Synucleins regulate the kinetics of synaptic vesicle endocytosis. J Neurosci 34:9364-9376

Varkey J, Isas JM, Mizuno N, Jensen MB, Bhatia VK, Jao CC, Petrlova J, Voss JC, Stamou DG, Steven AC, Langen R (2010) Membrane curvature induction and tubulation are common features of synucleins and apolipoproteins. J Biol Chem 285:32486-32493

Varkey J, Mizuno N, Hegde BG, Cheng N, Steven AC, Langen R (2013) $\alpha$-Synuclein oligomers with broken helical conformation form lipoprotein nanoparticles. J. Biol. Chem. 288:17620-17630

Vitali C, Wellington CL, Calabresi L (2014) HDL and cholesterol handling in the brain. Cardiovasc Res 103:405-413

Wang H, Eckel RH (2014) What are lipoproteins doing in the brain? Trends Endocrinol Metab 25:8-14

Wang ES, Sun Y, Guo JG, Gao X, Hu JW, Zhou L, Hu J, Jiang CC (2010) Tetranectin and apolipoprotein A-I in cerebrospinal fluid as potential biomarkers for Parkinson's disease. Acta Neurol Scand 122:350-359 